\title{
Can Myrmica rubra Ants Use Tools or Learn to Use Them?
}

\author{
Marie-Claire Cammaerts ${ }^{1}$ \\ ${ }^{1}$ Retired from Department of evolutive eco-ethology, University of Brussels, Belgium \\ Correspondence: Marie-Claire Cammaerts, 27, Square du Castel Fleuri, 1170 Bruxelles, Belgium. E-mail: \\ mccammaerts@gmail.com
}

Received: December 14, 2016

Accepted: December 17, 2016 Online Published: December 21, 2017

doi:10.5539/ijb.v10n1p1

URL: https://doi.org/10.5539/ijb.v10n1p1

\begin{abstract}
The aim of this study was to define the limit of ant cognition, and we examined whether Myrmica rubra ants could use tools or learn to use them. We presented the ants with 1) a piece of mealworm inserted into a small tube tied to a thread that had to be pulled for easy access to the mealworm; 2) a plug that closed the entrance of the ant sugar water tube provided with two push-pieces that had to be pushed to remove the plug from the entrance; and 3) a plug, closing the nest entrance, provided with a thread that had to be pulled to remove the plug. The ants could not use these "proto-tools". After exposure to proto-tools having been used, some ants interacted with them, shortly, not efficiently. During the first experiment, the ants received the larva progressively inserted further into the tube, and interacted with the proto-tool more than during the two other experiments. Therefore, Myrmica rubra ants might be able to use some proto-tools following long-lasting habituation, imitation or conditioning processes, which would not be a strictly use of tools. Thus, ant cognition in this species extended up to but did not include the use of proto-tools, and at fortiori of sensu stricto tools.
\end{abstract}

Keywords: Cognition, Conditioning, Learning, Myrmica rubra, Proto-tool

\section{Introduction}

Tool use is a trait of high interest for ethologists. Because humans can use tools and can learn to use them, many researchers examine animals for these abilities, generally in vertebrates but also recently in invertebrates (Pearce, 2008). Ethologists differ in the definition of "tools." In his review of tool use in insects, Pierce (1986) defines the "tool use" as "Tool use may be classified as the active manipulation of an object which alters efficiently the condition of another object or an organism. Definitional boundaries may lead to discussion" (Pierce, 1986). The definitions of Bentley-Condit \& Smith (2010), Jost (2015), and Haslam (2013) imply that a sensu stricto tool is initially separated from the user and from the object to be manipulated, and as a consequence, the user must find, then hold, and finally use the tool to change the location, the form, the content or any other characteristic of an object or an individual. Monkey species can correctly use and can learn to use a tool (Beck, 1973), similarly for Ara parrot species (Shumaker, Walkup, \& Beck, 2011). Dogs, dolphins, elephants can use tools but must be trained (McFarland, 2009). No similar behaviors have been observed or experimentally obtained among less evolved vertebrates. Among invertebrates, behaviors approaching the strict use of tools (see the above definition) have been recently described, and has been attempted to be obtained in social hymenopterans (references below). Social bumblebees rarely pull a string to obtain sugar water, but these bees can learn this behavior when trained to perform the task during a relatively long period by operant conditioning in a stepwise manner. Naïve bumblebees can also acquire this behavior simply by observing nestmates performing the task (Alem et al., 2016). Demonstrated experimentally, bumblebees can also learn to push a ball into a hole to obtain sugar food (https://www.theguardian.com > Science > Animal behavior; Loukola, Perry, Coscos \& Chittka, 2017). Among the ants, the following behaviors have been considered "using tools" by the authors of their description. The worker ants of the genus Oecophylla build their nest based on complex cooperation: these ants place the borders of leaves close together and then tie the borders by holding their larvae which produce sticky silk (Cole, Jones, \& Jones, 1948; Passera, 2008). Conomyrma bicolor workers set soil material in the nest entrance of honey pot ants of the genus Myrmecocystis, and while workers of the latter genus remove the soil material, C. bicolor workers take away some honey food (Möglich \& Alpert, 1979). Allomerus decemarticulatus capture large prey by collectively building a type of trap (Dejean, Solano, Ayroles, Corbara, \& Orivel, 2005). All these complex behaviors resembling some tool use are collectively exhibited and progressively acquired by the species. Some ant species collect sugar water by dropping in some material that becomes soaked with sugar liquid, which is then transported to the nest [references below]. More precisely, the observations of Morille on Pogonomyrmex badius (Morril, 1972), 
those of Fellers and Fellers on Aphaenogaster rudis, A. treatae, A. tennesseensis and A. fulva (Fellers \& Fellers, 1976), and of those Banschbach et al. on A. rudis (Banschbach, Brubelle, Bartlett, Grivetti \& Yeamans, 2006) revealed that a small proportion of the workers of these species transport liquid food via debris, fragments, and pellets of sand imbibed with the liquid, which is a behavior labeled "foraging tool use." However, the ants showing this behavior do not use the same fragment again for transporting more liquid food. Thus, their behaviors are not strictly "tool use." Some of these ants can improve the technique. When workers of Aphaenogaster subterranae and A. senilis are provided with a honey solution and different materials allowing collecting this honey, first, the ants use all the materials and then progressively select the best ones (Karath, 2016), and although this behavior is not strictly "using tools," tool use is approached.

Ants are good models to examine the potential use of tools by evolved insects. They are eusocial and collectively accomplish complex tasks such as building sophisticated nests, recruiting nestmates, differently marking their nest, their nest entrances and their foraging area, acquiring conditioning, acquiring spatial and temporal learning as well as spatio-temporal conditioning, estimating the distance walked, and navigating using memorized visual and olfactory cues (Hölldobler \& Wilson, 1990). Ants even might recognize themselves in a mirror (M.-C. Cammaerts \& R. Cammaerts, 2015a) and can expect the location and the time of subsequent food delivery on the basis of previous deliveries (M.-C. Cammaerts \& R. Cammaerts, 2016a; M.-C. Cammaerts \& R. Cammaerts, 2016b). The ontogenesis of some of these abilities has been unraveled (M.-C. Cammaerts \& R. Cammaerts, 2015b). The ant brain is highly sophisticated and allows performing multiple and complex acts (Straufeld, 1976). Working with the ant Myrmica ruginodis Nylander 1846, we showed that workers can solve some simple problems: they could walk round a barrier, walk preferentially on smooth substrates instead of rough ones, establish one-way paths when only two narrow paths for going in and out of their nest were available, and push a door to access sugar water (Cammaerts, 2017a). Thereafter, we observed that they could learn novel behaviors, although such behaviors were not initially exhibited: they learned to wet solid sugar or to sweeten pure water to collect sugar water, to open a double door nearly shutting their sugar water tube entrance, and to enlarge a narrow path through a thin cotton barrier plugging their nest entrance (Cammaerts, 2017b).

After demonstrating that ants can solve simple problems acting according to their behavioral repertory (Cammaerts, 2017a) and can learn through conditioning and imitation some simple new methods (Cammaerts, 2017b), we wanted to proceed a further step and examine whether the ants could perform some more difficult tasks. More precisely, in this study, we determined whether the ant species, Myrmica rubra Linnaeus 1758, under experimental circumstances could use some type of "tool" (a "proto-tool," which is a tool already tied to the object to be handled) or could learn to use it with efficiency. We confronted workers of this species with meat food attached to a thread and inserted into a very narrow tube, with a sugar water tube shut by a paper plug provided with push-pieces, and with the nest entrance shut by a paper plug provided with a thread. For Myrmica rubra, the ecology, food recruitment system, navigation method, conditioning ability, eyes morphology, visual perception, spatio-temporal learning, imitation ability, self-recognizing capability, process of some cognitive abilities acquisition, and ability in expecting food delivery on the basis of previous deliveries, among other aspects, are well documented (M.-C. Cammaerts \& D. Cammaerts, 2014; Cammaerts, 2013a; and references above].

Below, after the explanation of our methods and related results, we analyze the results, and accounting for the notions and findings described above, in addition to some ethological knowledge, we respond to the question "can M. rubra ants use tools or learn to use them?" and simultaneously define the extent of the cognitive abilities of these insects.

\section{Material and Methods}

\subsection{Collection and Maintenance of Ants}

The experiments were performed on two colonies of M. rubra collected in the Aise Valley (Ardenne, Belgium) in May 2017. The ants nested in grassland under stones; the colonies contained approximately 600 workers, 1-2 queens and brood. The colonies were maintained in artificial nests constructed of 2-3 glass tubes half filled with water, with a cotton plug separating the ants from the water. The nest tubes of each colony were deposited in a tray ( $34 \mathrm{~cm} \times 23 \mathrm{~cm} \times 4 \mathrm{~cm}$ ), with the internal sides slightly covered with talc to prevent ant escape. The trays served as foraging areas into which food was delivered. Ants were fed with an aqueous solution of sugar (30\%) permanently provided in cotton-plugged glass tubes (diameter: $1.5 \mathrm{~cm}$; length: $7 \mathrm{~cm}$ ) and cut Tenebrio molitor larvae (Linnaeus, 1758) provided three times per week. Laboratory temperature was $18-22{ }^{\circ} \mathrm{C}$, and the air relative humidity was approximately $80 \%$. The lighting intensity equaled 320 lux while caring of and testing the ants. During other times, natural light was provided and varied from 5 to 120 lux according to the time of day. The intensity of the EMF in the laboratory equaled $2-3 \mu \mathrm{W} / \mathrm{m}^{2}$. The ants are called "nest mates," consistent with the common usage of persons working on social insects. 
A
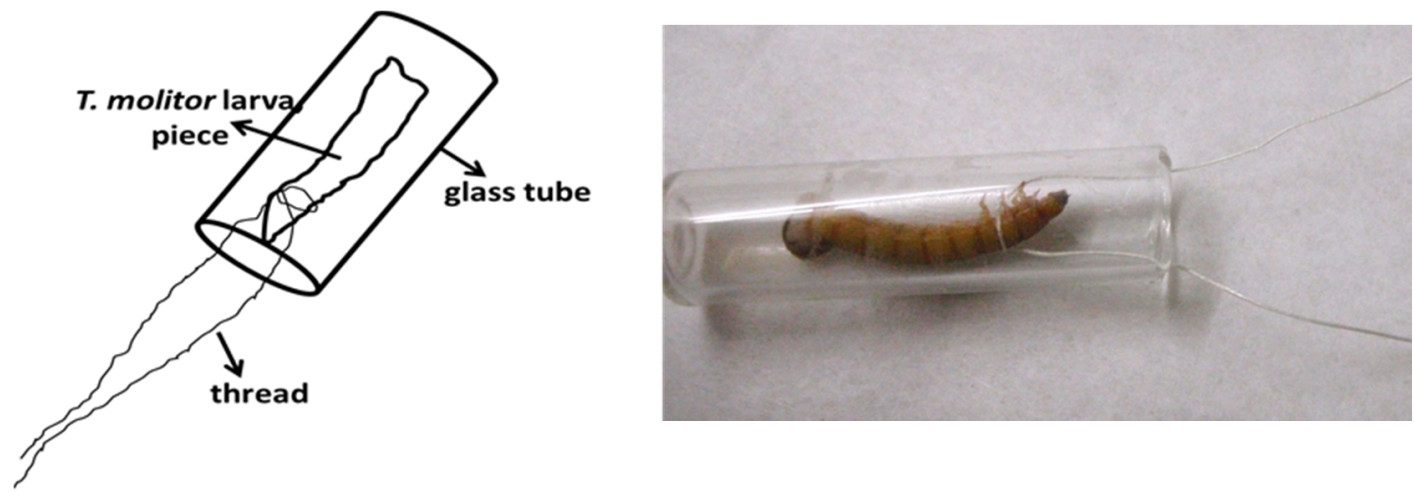

B
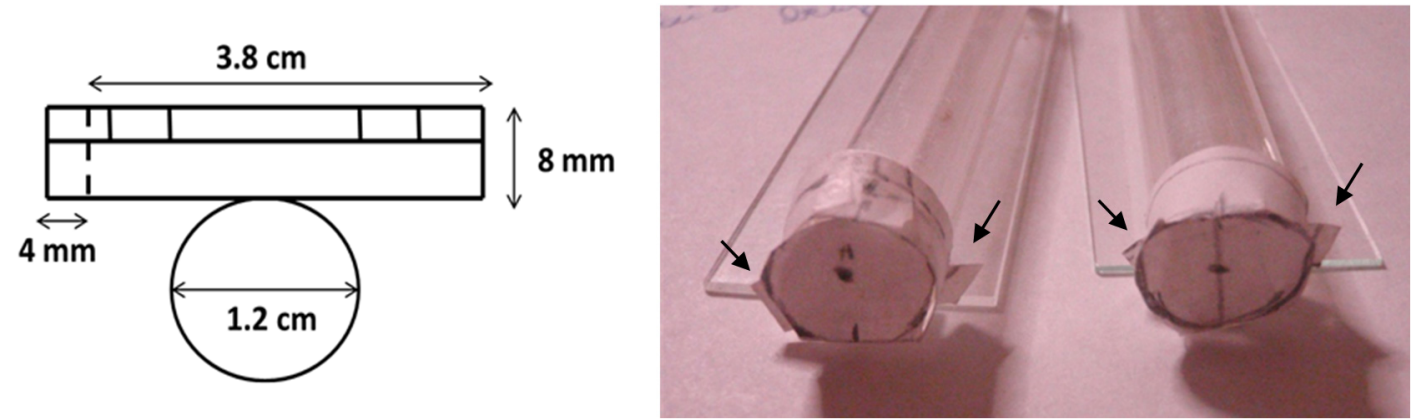

C
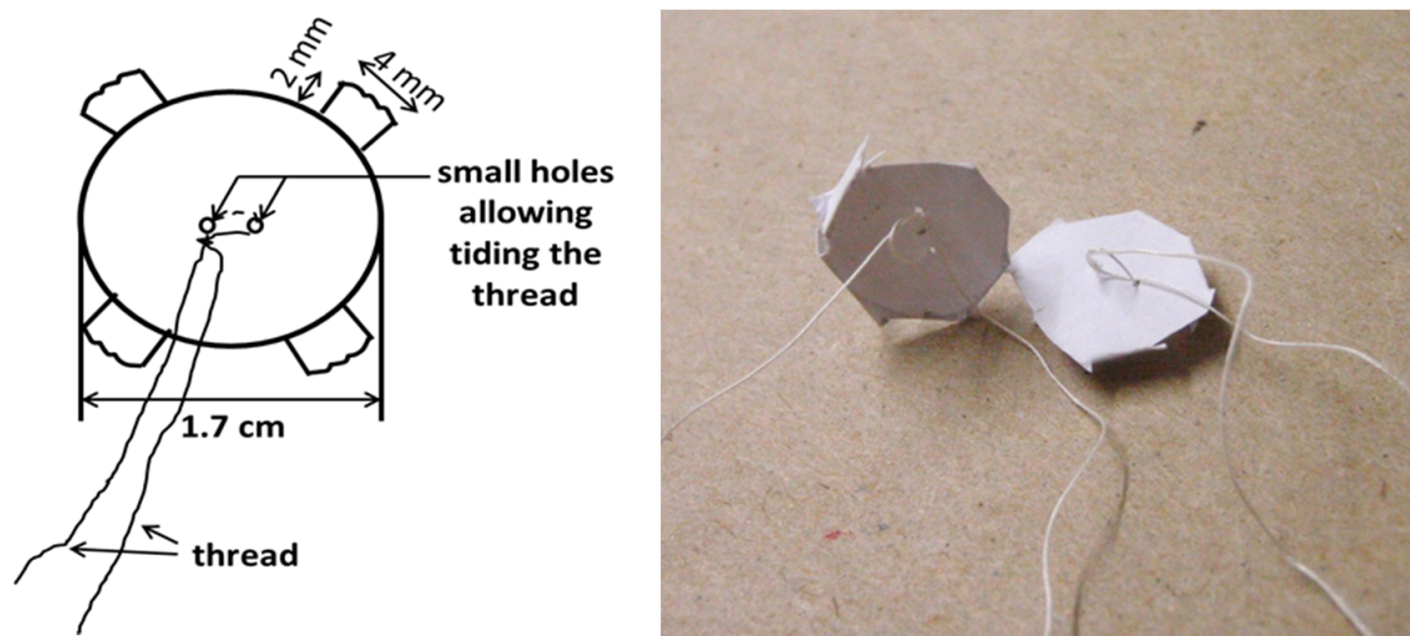

Figure 1. Diagrams and photos of the three (A, B, C) experimental apparatuses used in this study. A: A cut $T$. molitor larva tied to a thread and inserted into a tube was presented to ants to determine whether they could obtain the larva by pulling the thread. B: A paper plug was used to (weakly) shut the entrance of a sugar water tube to determine whether ants could successfully push on the push-pieces (arrow) and remove the plug. C: A paper plug, with sewing thread attached, was set in the nest entrance (see Figure 2C) to examine whether ants could pull

(moving head forward or backward) the thread to remove the plug

\subsection{A Thread Tied to Meat Food}

An experimental apparatus was built for each colony. A T. molitor larva was cut at $3 / 4$ of its length, and a cotton sewing thread $(6 \mathrm{~cm}$ long) was tied to its thorax. This tied larva was inserted into a glass tube (diameter: $7 \mathrm{~mm}$; length: $3 \mathrm{~cm}$ ) with the head near the entrance, the cut section near the bottom of the tube, and the two free parts of the thread ( $3 \mathrm{~cm}$ long) lying outside (Figure 1A). This apparatus was presented to the ants where pieces of $T$. molitor larvae were normally provided as meat, with any remaining pieces removed a few hours before the apparatus presentation. The apparatus was presented six successive times, each time with a new mealworm piece. The apparatus was first presented as described above, i.e., with the cut larva fully inserted inside the tube, and the thread parts outside in the ant foraging area (= initial presentation). The apparatus was presented a second time with the larva out of the tube (= the solution). Thereafter, the apparatus was presented with the cut larva inserted in the tube successively at $0.5,1.0,1.5$, and $2.0 \mathrm{~cm}$ from the entrance, with these four presentations offered on four 
successive days. To be clear, the successive aspects of the experimental apparatus were prepared in the absence of ants; thus, the ants did not witness the preparation of the apparatus. Each presentation lasted 30 minutes, and ant behavior was observed and quantified as explained below. At the end of the fourth test presentation, the apparatus remained in place for four hours and was then examined to detect any change in its initial state. The mealworm piece was finally given as food to the ants, and the experiment ended.

\subsection{A Plug Shutting Access to the Sugar Water Supply}

An experimental apparatus was built for each colony. A usual sugar water tube was shut with a plug of white paper. The plug was composed of a circular part (diameter: $1.2 \mathrm{~cm}$ ) and a rectangular one that was curved to form a ring encircling the tube entrance (Figure 1B, left drawing). When in place, the circular part of the paper plug was immediately in front of the tube entrance, shutting it (Figure 1B, right photo). The rectangular part of the plug was partly cut at four places to provide two fragments, which were orthogonally folded to form two push-pieces (4 $\mathrm{mm} \mathrm{x}$ $2 \mathrm{~mm}$ ). Very slight pressure on these push-pieces removed the plug. In this experiment, to be effective, the ants were expected to push on the two "push-pieces" to remove, at least partly, the plug shutting access to the sugar water tube. This apparatus was presented to the ants (in the usual location of the sugar water feeder, which was removed a few hours before) seven successive times. The apparatus was first presented as described above, with the plug on the tube (= initial presentation). The apparatus was then presented with the plug removed from the tube and set immediately to the side of the tube (= the solution). Thereafter, the apparatus was presented with the plug on the tube entrance in five successive test presentations on five successive days. The successive aspects of the experimental apparatus were prepared in the absence of ants, which therefore did not observe the preparations. Each presentation was 30 minutes, and ant behavior was observed and quantified as explained below. After the fifth test presentation, the apparatus remained in place for four hours and was then examined to detect any change in its initial aspect. The plug was then removed from the sugar water tube, which was then set on the ant tray, and the experiment ended.

\subsection{A Thread for Removing a Plug Shutting the Nest Entrance}

An experimental apparatus was built for each colony. The nest entrance was shut with a piece of paper composed of a circular part (diameter: $1.7 \mathrm{~cm})$ and four small parts $(4 \mathrm{~mm} \times 2 \mathrm{~mm}$ ) that extended from the circular part (Figure 1C, left drawing). With the four small parts orthogonally folded (Figure 1C, right photo) and inserted into the nest tube entrance, the circular part was maintained in the entrance, i.e., shutting the nest entrance (Figure 2C, C'). Two very small holes were pierced in the center of the circular part of the apparatus. A sewing cotton thread was passed through one of these holes, going in the same direction as the folded four small parts, then was passed through the other hole, going in the other direction, and a noodle was formed, leaving free two thread extremities 3 $\mathrm{cm}$ long (Figure 1C, left and right elements). Pulling the thread, moving with the head backward or forward, each time in the correct direction, removed the paper plug from the nest entrance, which was the expected behavior of $M$. rubra ants. The experimental apparatus was presented seven successive times to the ants. First, the apparatus was presented as described above, i.e., the plug shutting the nest entrance (= initial presentation). Second, the apparatus was presented with the plug removed from the entrance and set immediately to the side of the tube (= the solution). Thereafter, the apparatus was presented with the plug set in place, with five test presentations on five successive days. The successive aspects of the experimental apparatus were prepared in the absence of the ants, which therefore only saw the apparatus already prepared for the test. Each presentation lasted 30 minutes, and the ant behavior was observed and quantified as explained below. After the fifth test presentation, the experimental apparatus, with the plug shutting the nest entrance, remained in place for four hours and was then checked for any changes caused by the ants. The plug was then removed from the nest entrance, and the experiment ended.

\subsection{Assessment of Ant Behavior}

As a preliminary comment, the behaviors of ants were not predicable; thus, we could not set adequate variables assessing some given behavior, and only some basic quantification was performed. During each experimental apparatus presentation (30 minutes), the ants of each colony which were on, in front of and immediately to the side of the apparatus, and separately the ants interfering with the thread or the push-pieces (touching, gripping, pulling moving backward or forward, or pushing on the push-pieces) were counted at the end of each minute. The ants attacking (biting, stinging) the experimental apparatus were not numerous and not counted. Importantly, note that the control experiment was the "initial" presentation. For each apparatus presentation, the mean number of ants of the two colonies present at a time on or very near the apparatus, and the mean number of ants interfering with the thread or the push-pieces were established (Tables 1, 2, 3). Using these two mean numbers, the proportion of ants among those present was calculated that touched, gripped, and pulled moving backward or forward on the thread or pushed the push-pieces. Such proportions obtained for the initial (the control), the "solution" and the four or five 
following successive presentations were plotted with the successive presentations (Figure 3), and the curves were compared with those describing known behavioral processes (Pearce, 2008).

Table 1. Behavior of ants in front of a larva inserted inside a small tube and attached to sewing thread that had to be pulled to have easy access to the larva

\begin{tabular}{lccccccccc}
\hline \multirow{2}{*}{ Presentations } & \multicolumn{3}{c}{ Ants present $(=\mathbf{p})$} & & \multicolumn{3}{c}{ Ants interacting $(=\mathbf{i})$} & \multirow{2}{*}{ i/p } \\
\cline { 2 - 3 } & $\mathrm{A}$ & $\mathrm{B}$ & mean & & $\mathrm{A}$ & $\mathrm{B}$ & mean & \\
\hline Initial & 86 & 157 & 4.04 & & 0 & 0 & 0.00 & 0.00 \\
Solution & 72 & 164 & 3.93 & & 0 & 0 & 0.00 & 0.00 \\
Test 1 & 74 & 111 & 3.08 & & 11 & 19 & 0.50 & 0.16 \\
Test 2 & 71 & 98 & 2.82 & & 14 & 17 & 0.52 & 0.18 \\
Test 3 & 55 & 57 & 1.87 & & 17 & 15 & 0.53 & 0.29 \\
Test 4 & 50 & 79 & 2.15 & & 18 & 17 & 0.58 & 0.27 \\
\hline
\end{tabular}

The table gives the number of ants (colonies A and B) on the apparatus (sum of 30 counts each time) and of ants interacting (gripping, pulling by moving the head backward or forward) with the sewing thread and the proportion (i/p) of interacting ants among those present. The assessments are for 6 successive presentations: initial, larva $2 \mathrm{~cm}$ inserted; solution, larva out; tests $1,2,3$, and 4 : larva at $0.5,1.0,1.5$, and $2.0 \mathrm{~cm}$ from the tube entrance, respectively. The ants never used the thread to extract the larva from the tube, even after four hours.

Table 2. Behavior of ants in front of a paper plug shutting the sugar water tube and provided with two push-pieces that must be used to remove the plug

\begin{tabular}{|c|c|c|c|c|c|c|c|}
\hline \multirow{2}{*}{ Presentations } & \multicolumn{3}{|c|}{ Ants present $(=\mathbf{p})$} & \multicolumn{3}{|c|}{ Ants interacting $(=\mathbf{i})$} & \multirow{2}{*}{$\mathbf{i} / \mathbf{p}$} \\
\hline & $\mathrm{A}$ & $\mathrm{B}$ & mean & $\mathrm{A}$ & $\mathrm{B}$ & mean & \\
\hline Initial & 81 & 138 & 3.65 & 8 & 9 & 0.28 & 0.08 \\
\hline Solution & 106 & 315 & 7.02 & 0 & 0 & 0.00 & 0.00 \\
\hline Test 1 & 56 & 137 & 3.22 & 6 & 14 & 0.33 & 0.10 \\
\hline Test 2 & 58 & 86 & 2.40 & 12 & 13 & 0.42 & 0.17 \\
\hline Test 3 & 74 & 117 & 3.18 & 14 & 16 & 0.50 & 0.16 \\
\hline Test 4 & 73 & 90 & 2.72 & 17 & 15 & 0.53 & 0.20 \\
\hline Test 5 & 88 & 82 & 2.83 & 16 & 15 & 0.52 & 0.18 \\
\hline
\end{tabular}

The table gives the number of ants (colonies A and B) very near the plug or on it and of ants interacting (gripping, pushing) with the push-pieces (sum of 30 counts each time) and the proportion (i/p) of interacting ants among those present. The numbers are for 7 presentations of the apparatus: initial, tube shut; solution, plug removed, set to the side of the open tube; tests 1,2,3,4, and 5, with the tube shut each time. The ants never succeeded in removing the paper plug, even when the shut tube remained in place for four hours.

Table 3. Behavior of ants in front of a paper plug shutting the nest entrance and provided with a sewing thread that had to be pulled to remove the plug

\begin{tabular}{|c|c|c|c|c|c|c|c|}
\hline \multirow{2}{*}{ Presentations } & \multicolumn{3}{|c|}{ Ants present $(=\mathbf{p})$} & \multicolumn{3}{|c|}{ Ants interacting $(=\mathrm{i})$} & \multirow{2}{*}{$\mathbf{i} / \mathbf{p}$} \\
\hline & A & $\mathrm{B}$ & mean & A & $\mathrm{B}$ & mean & \\
\hline Initial & 83 & 100 & 3.05 & 5 & 7 & 0.20 & 0.07 \\
\hline Solution & 68 & 69 & 2.28 & 8 & 14 & 0.37 & 0.16 \\
\hline Test 1 & 52 & 112 & 2.73 & 7 & 13 & 0.33 & 0.12 \\
\hline Test 2 & 93 & 70 & 2.72 & 15 & 12 & 0.45 & 0.17 \\
\hline Test 3 & 103 & 76 & 2.98 & 22 & 15 & 0.62 & 0.21 \\
\hline Test 4 & 69 & 137 & 3.43 & 13 & 24 & 0.62 & 0.18 \\
\hline Test 5 & 107 & 104 & 3.52 & 14 & 19 & 0.55 & 0.16 \\
\hline
\end{tabular}

The table gives the number of ants (colonies A and B) in front of or on the apparatus (plug + thread) and of those interacting (touching, gripping, pulling moving the head backward or forward) with the sewing thread and the proportion ( $\mathrm{i} / \mathrm{p}$ ) of interacting ants among those present. The numbers are for 7 successive presentations of the apparatus: initial, tube shut; solution, plug removed and set to the side of the open tube; tests 1, 2, 3, 4, and 5, with the tube shut each time. The ants never succeeded in removing the plug, even when the apparatus remained in place for four hours. 


\section{Results}
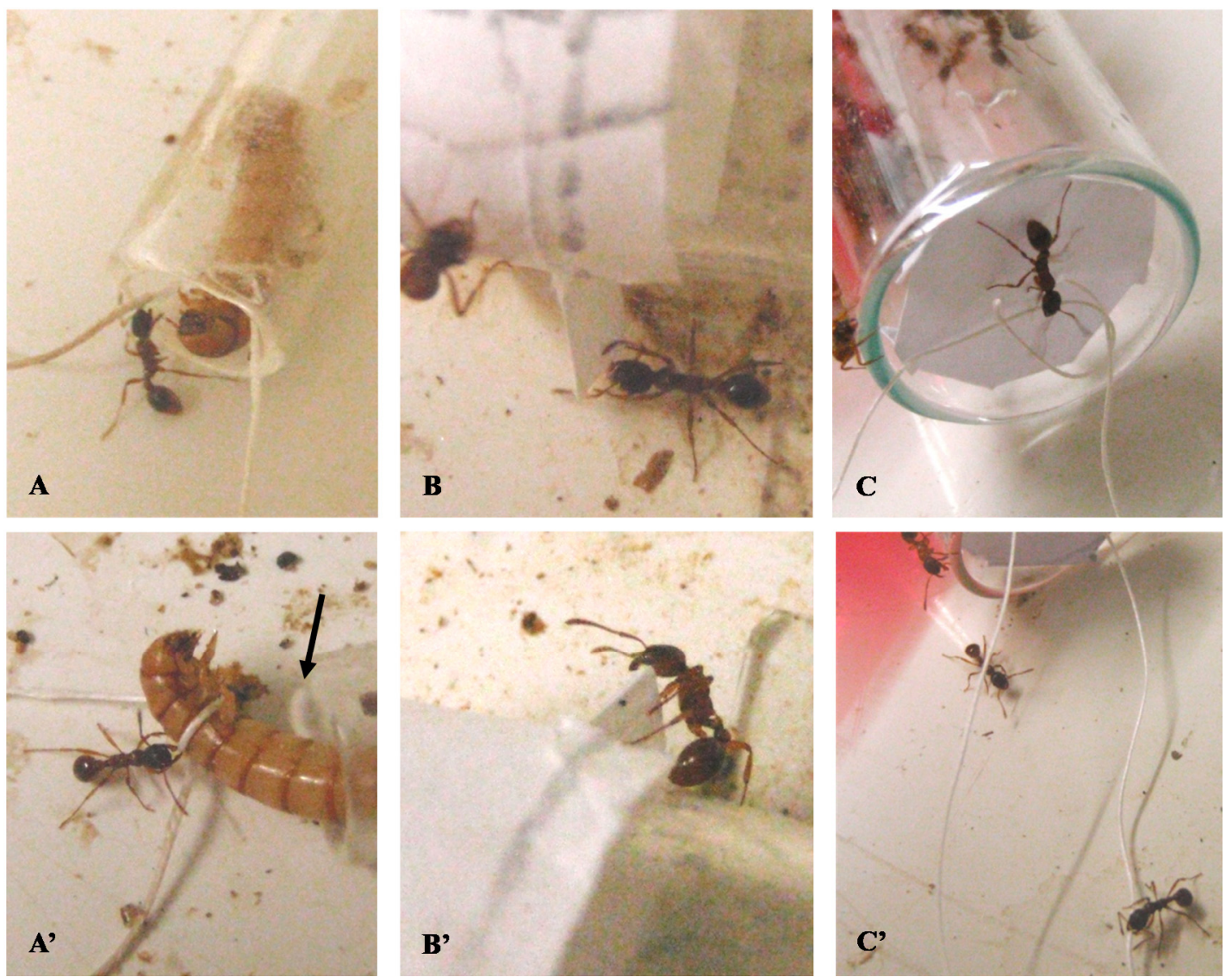

Figure 2. Some views of the three experiments (A, A'; B, B'; C, C') conducted with Myrmica rubra. A: An ant in the nick of gripping a thread tied to a cut T. molitor larva but at an inadequate distance from the larva to succeed; $\mathbf{A}^{\prime}:$ An ant gripping the thread and pulling it, moving the head backward. The ants never succeeded in extracting the larva from the tube. Arrow: Some hemolymph was leaking from the larva. B, B': An ant pushing on a push-piece of a paper plug set in the sugar water tube entrance. The ants never succeeded in removing the plug. C: An ant on a paper plug shutting the nest entrance and unable to manipulate the thread tied to the plug, which should be pulled to remove the

plug; C': An ant pulling the thread moving the head forward. The ants never removed the plug. Thus, for each experiment, the ants could not use the presented proto-tool, although weakly interacting with the proto-tools

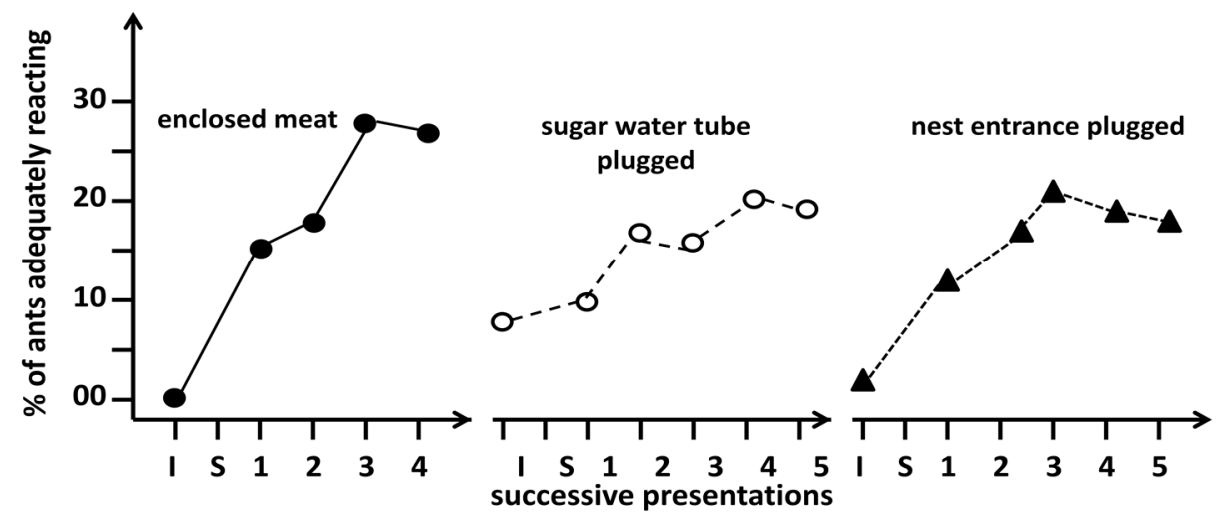

Figure 3. Proportions of Myrmica rubra ants among those present interacting with a "proto-tool." Experimental protocols and the results are detailed in the text. The numerical results are given in tables 1,2, and 3; schemas and photos are presented in figures 1 and 2 . Briefly, the ants very slightly and not efficiently interacted with the presented proto-tools. Thus, using such objects by themselves was, in these circumstances, beyond the limit of their cognitive abilities 


\subsection{Pulling on a Thread to Obtain Meat Food}

When the ants were confronted for the first time with a T. molitor larva inserted in a tube, they were very numerous around this object, but no ant interacted (gripped, pulled moving with head backward or forward) with the thread tied to the larva. Presented with the solution (i.e., the T. molitor larva out of the tube and the empty tube immediately to the side), the ants were also numerous around these objects, and no ant touched the thread (Table 1, initial and solution presentations). Then, when the ants were confronted with a larva partly and then progressively more and more inserted into the tube, they were a little less numerous than previously around the apparatus (Table 1 , test presentations), and several workers interacted for a time with the thread tied to the larva (Figure $2 \mathrm{~A}, \mathrm{~A}^{\prime}$ ). The proportion of interacting ants increased from 0.16 to 0.29 over the first three test presentations, with no further increase during the fourth test presentation $(0.27$; Table 1$)$. Thus, approximately $1 / 3$ of the ants that observed the inserted larva interacted with the thread (which had to be pulled to extract the larva from the tube). However, these interactions were inefficient, and the ants were not sufficiently numerous to be efficient. Ants also pulled on the thread for too short time periods and even pulled on the thread with their legs on it, which was an inefficient procedure. Sometimes, the ants pulled the thread moving in the wrong direction and also tried to grip the thread too close to the larva (Figure 2A). These behaviors all suggested that the ants could not guess that they should grip the thread at approximately $1-2 \mathrm{~cm}$ from the larva and then pull on it moving (with the head backward or forward) away from the tube. Consequently, based on the observations and numerical results, the deduction was that the ants could not determine how to use the thread and could not learn how to use the thread to obtain easy access to the mealworm.

Based on mathematical analysis, the proportion of ants interacting with the thread increased over time (Figure 3, left graph), somewhat like what might be expected during a habituation or a conditioning process (Pearce, 2008). However, this proportion of ants never reached the high levels (60-80\%) generally observed after some habituation or conditioning process. Thus, the ants did not effectively go through some habituation or conditioning experience, although a slight tendency was observed. This speculation is discussed further in the following "Discussion" subsection.

After the tube with the fully inserted larva had remained in place for four hours in the ant foraging area, the location of the larva was unchanged. Thus, we concluded definitively that $M$. rubra ants did not learn how to use this experimental apparatus, although some acts suggested that learning might be possible. The two following experiments were conducted to verify this hypothesis, which is then discussed in a subsequent ' 4 Discussions' subsection.

\subsection{Pushing on the Push-Pieces of a Plug to have Access to the Sugar Water Supply}

Confronted for the first time with the sugar water tube shut with a paper plug provided with two push-pieces, the ants were very numerous around the apparatus but scarcely interacted with the push-pieces of the plug (Table 2, initial). When the sugar water tube was opened and the plug was set apart, the ants were numerous around these objects but not one interacted with the push-pieces, which was reasonable behavior (Table 2, solution). When presented again with the sugar water tube shut, ants were more numerous in interacting with the push-pieces (Table 2, test 1; Figure 2B, B'). Thereafter, for the three following experimental apparatus presentations, the proportion of ants interacting with the push-pieces increased (Table 2; tests 2,3,4). Then, during the fifth presentation, this proportion equaled only the low value of approximately $18 \%$ (Table 2 ; test 5 ). Consequently, approximately $20 \%$ of the ants coming onto the apparatus adequately pushed on the push-pieces. Thus, the ants were not sufficiently numerous to efficiently use these push-pieces. Ants also pushed for too short time periods, and therefore, the ants never successfully removed the paper plug shutting the sugar water tube.

Based on mathematical analysis, the proportion of ants interacting with the experimental apparatus increased over time, (Figure 3, second graph) producing a curve that resembled those of habituation or conditioning of very poor quality. This statement is discussed in the following "Discussion" subsection.

The experimental apparatus remained in place for 4 hours after the fifth presentation. The ants continued to move around and on the apparatus and continued to interact inefficiently with the push-pieces. Finally, ants moved away from the apparatus, and the plug remained in place. Thus, M. rubra ants did not correctly use the experimental apparatus. This deduction corroborated that of the first experiment and was followed by a third type of experiment, before being discussed in a subsequent '4 Discussions' subsection.

\subsection{Pulling a Thread to Remove a Plug Shutting the Nest Entrance}

Confronted for the first time with their nest entrance shut, the ants erratically moved around the entrance, on the plug, on the thread tied to that plug, but scarcely interacted with the thread (Table 3, initial). With the front of their 
nest entrance open and the plug set immediately to the side, the ants interacted somewhat with the plug (Table 3, solution). When confronted again with their nest entrance shut, the ants interacting with the thread attached to the plug were relatively numerous, gripping and pulling the thread moving the head backward or forward in the correct but sometimes in the wrong direction (Table 3, test 1; Figure 2C, C'). The proportion of ants interacting with the thread increased in the two following test presentations (Table 3, tests 2,3). Then, the proportion decreased somewhat in the last two test presentations (Table 2 , tests 4,5 ). Consequently, only $16-21 \%$ of the ants very shortly (a few seconds) interacted with the thread, which was not sufficient to remove the plug from the nest entrance.

Based on mathematical analysis, the proportion of ants interacting with the experimental apparatus varied over time according to a curve resembling that of some habituation or conditioning process of very poor quality (Figure 3 , third graph), which is discussed in the following "Discussion" subsection.

After the fifth presentation, the experimental apparatus remained in place for four hours. The ants never succeeded in removing the plug from their nest entrance. These results led to the conclusion that $M$. rubra ants did not use and did not learn to use the experimental apparatus, corroborating the deduction reached for the two previous experiments. In the below subsection ' 4 Discussions', the details of our experiments are analyzed, and the results of the three experiments are compared to clarify this deduction. Finally, using all available information on the subject, a conclusion is proposed in that subsection and is then better defined in the subsequent 5 Conclusion' section.

\section{Discussions}

Briefly, in the present work, M. rubra ants were placed in specific situations that required the use of a proto-tool. Then, with exposure to that proto-tool fully or partly used, the behavior of workers placed again in the initial, or nearly initial, situation requiring the use of the proto-tool was examined for changes, and the behavior of a few workers changed somewhat. Whether some behavioral changes occurred, neither a single ant nor all the ants together could efficiently use the presented proto-tools. The study examined three experimental situations, each time on two large colonies of M. rubra. Thus, this conclusion is valid only for this species and these experimental circumstances. Although a trend of an increase of reacting ants was observed each time, the observations were not validated by statistics. However, this increase (and never a decrease or no change) occurred for each of the two colonies used and during each of the three experiments. The probability of a random occurrence of this observed increase was $(1 / 3 \times 1 / 3 \times 1 / 3)^{2}=1 / 81=0.01$. Thus, the interactions of ants with the proto-tools effectively increased, but no further conclusions could be deduced.

The cognitive abilities of colonies are different, generally between colonies living on different sites but also between colonies living on the same site (Cammaerts, 2017c). In the present study, two colonies living nearly side by side on the same site were used to reduce the inter-colonial variability, although two large colonies was a small sample. Working with small samples is relatively frequent in ethology, and non-parametric statistics are used (when possible) for data analysis. Future experiments on the subject should be conducted using several demographically equivalent fragments of a large colony, which would increase the sample size without enlarging the variability.

During each experiment, we observed that not all the ants interacted with the proto-tools: some ants were active, whereas other ants were less active. Such variability is due to some idiosyncrasies occurring in any social group and to age-based differences, with the younger ants less capable than the older ones (Cammaerts, 2013b; Cammaerts \& Gosset, 2014). For each experiment, based on observations, renewed access to the supply of sugar or to their nest entrance was the apparent goal of all ants, but most ants could not guess how to proceed; and although a few ants might have somewhat recognized the problem, guessed more or less what was required and tried to solve the problem, the ants never succeeded in efficiently completing the required tasks.

A difference was observed between the first experiment and the two following ones: the proportion of ants acting correctly was larger at the end of the first experiment than at the end of the other two. This difference was most likely due to the particular protocol of the first experiment in which the ants were successively shown the food progressively inserted into the tube. Perceiving these progressive changes of the experimental apparatus (first experiment), the ants could react somewhat better than when only seeing the "solution" at once (i.e., a plug removed) (second and third experiments) and not step by step. Progressively removing the plug shutting the sugar water tube or the nest tube was not experimentally possible; any opening, even small, and the ants could enter the tubes. Based on this observed slight difference between the first and the two other experiments, the limit of ant capability to learn to use "proto-tools" could be defined (see the explanation below).

There are three levels of "learning". The first level is habituation, which generally occurs in front of unknown stimulus of weak intensity with which the animal has frequent contacts and which can be avoided by the animal (by 
moving away and stopping the reaction). With habituation, after some time, the animal stops reacting. The second level of learning is conditioning, i.e., the association between a known rewarding element and another one. This requires some cognitive processes by which behavioral changes are acquired and which then act on environmental elements. This second level of learning is widespread and because it allows an organism adapting itself to environmental changes, it is very important for the survival of a species. The third level of learning is the result (at least partly) of intuition, and such learning requires cognitive abilities that allow analysis of a current situation, remembering previous experiences, and then acting (and memorizing the acts) correctly very quickly, with no long-lasting "essays and errors" time period. In our present experiments, the ants behaved generally under a habituation process (for example, after a few hours, the ants left the apparatus) and very weakly and poorly under a conditioning process (because no reward was provided after each correct reaction). However, the ants behaved with somewhat more conditioning (of poor quality) during the first experiment than during the following two, most likely because the ants were provided with a little reward (see below). Note that, for each experiment, the ants "understood" that they could not solve the problem and therefore stopped attempts. Additionally, nestmates can influence any ant, which is a consequence of sociality. This exists in nature and cannot be avoided even in novel experiments on the subject. In fact, in social insects, only potential collective and not individual proto-tool use can be studied.

As for the limit of ant cognitive abilities, the limit may be reached before the use of proto-tools, which might be acquired from long-lasting operant conditioning with effective rewarding (which is not a sensu stricto use of any tool). Indeed, during the first experiment, some training was tempted, in contrast to the other two experiments: the food was progressively more inaccessible, and some mealworm larva hemolymph might have leaked from the tube containing the cut larva and slightly imbibed the thread; we observed that the surroundings of the larva were wet (Figure 2A', arrow). Therefore, ants might have been somewhat rewarded. In the other two experiments, the ants did not receive any reward. With a suitable type of training, it is possible that some ants could ultimately learn to use "proto-tools" in specific circumstances. However, this presumption requires experimental verification. Novel experiments on small ant groups (see above) should set these groups in situations requiring proto-tool use learned step by step, with some reward received for each correct reaction. In this type of experiment, ants might learn to use proto-tools through conditioning, i.e., being rewarded each time they act correctly. However, these ants may then be unable to generalize their "conditioned" use of proto-tools to other circumstances in a different environment. Thus, the ants may be unable to assimilate the proto-tool as an element that can be used elsewhere for solving a similar problem, and their "learning" to use tools through conditioning would be only conditioning and not a sensu stricto acquisition of a general use of a tool. Briefly, some types of learning (classical conditioning, operant conditioning) step by step with rewards and with several repetitions, day after day, might lead to some correct responses, similar to those allowing the use of tools; however, to the ants, the status of the "tool" would be something associated with the reception of a reward. Overall, true learning of a sensu stricto tool use is apparently impossible for ants. We showed previously that ants are capable of associative learning, memorization, and performing several simple innate behaviors (Cammaerts \& Cammaerts, 2014), and that ants can imitate (Cammaerts, 2013a) and learn in the presence of experienced nest mates (Cammaerts \& Cammaerts, 2015b). We revealed that the ants can solve simple problems acting according to their behavioral repertory (Cammaerts, 2017a) and can acquire some novel techniques (Cammaerts, 2017b). Here, we showed that the ants were at the limit of using and of learning to use sensu stricto proto-tools and concluded that their cognitive abilities did not include tool use.

In the works of other researchers, some ant species succeed in performing tasks approaching tool use (Lörinczi, 2014; Maaka et al., 2017; Bussing, 2017; and references therein]. However, these tasks cannot be considered using sensu stricto tools. The works here above cited also note that behavioral differences occur between ant species. Therefore, we recall that the present work (and the following conclusion) is valid only for M. rubra ants and for the given experimental situations.

A limit of cognition similar to that of ants is apparent in bumblebees. Alem et al. (2016) showed that 1) bumblebees (Bombus terrestris) rarely pulled a string tied to some sugar water supply to obtain it, 2) learned to pull the string when trained step by step for a long time, 3 ) learned through operant conditioning and never exhibited "insight" behavior, and 4) naïve bumblebees acquired the behavior after observing nestmates performing the behavior. These observations are consistent with those of our study.

Such a subtle limit at sensu stricto tool use is also observed among the primates: the less evolved species cannot strictly use a tool, whereas the most evolved primates can use a tool (e.g., the Chimpanzees) (https://fr.wikipedia.org/wiki/Bonobo). 


\section{Conclusion}

With the aim to provide new information on the cognitive abilities of ants, we examined whether ants of a given species, M. rubra, could use or could learn to use proto-tools provided in three specific experimental circumstances. The threads and the push-pieces provided to the ants to obtain their meat or to remove a plug were typical 'proto-tools' (not sensu stricto tools because they were already attached to the element to be changed) that had to be used, for the first time, individually and correctly. The expected acts of the ants are not in their behavioral repertory, and therefore, the thread and the push-pieces always remain tools. In this study, the situation of the ants differed from that of ants observed in a usual situation (building a nest, collecting honey food, capturing prey, collecting sugar liquid: see the introduction section). These situations also differed from those considered by other researchers (see the ' 1 Introduction' and the '4 Discussions' sections for references). In the present work, the ants did not use the presented proto-tools by themselves, and they very rarely, and not efficiently, learned to use them. The ants' inspection of the proto-tools clearly increased, and whether this change of behavior was only a simple increase of inspection or a step toward a proto-tool use is undetermined. The experimental situations that we and other researchers considered and the corresponding behaviors of the ants clearly show the extent of the cognitive abilities of the ants. Ants can use elements that are not tools or even proto-tools but cannot use elements that are effectively "proto-tools" and consequently sensu stricto tools, i.e., elements not yet attached to the object to be modified. If novel experiments on small groups of ants could obtain slight proto-tool use based on conditioning or any step by step learning, this result would not lead to the conclusion that ants can use proto-tools. It would be the result of a conditioning or a learning, while a sensu stricto tool use should be presented without previous learning, by the individuals, without external help, often showing some "insight behavior" (Pearce, 2008).

In conclusion, based on the present work, the limit of ant cognition occurs before the individual use of a sensu stricto proto-tool and before the individual memorization of an accidental de novo use of a tool and the conscious use of a sensu stricto tool. Consequently, we advance that the limit of ant cognition is located between "self recognition, collective use of very simple methods, use of several informative social signals (i.e., words), always acting using hereditably acquired behavior," and "awareness, individual use of sensu stricto tools and of techniques, with memorization of such uses, use of an informative social language (i.e., sentences), ability of improvising novel acts in never experienced situations."

\section{References}

Alem, S., Perry, C. J., Zhu, X., Loukola, O. J., Ingraham, T., Sovik, E., \& Chittka, L. (2016) Associative mechanisms allow for social learning and cultural transmission of string pulling in an insect. PLoS Biology, 14(10), e1002564. Retrieved from http://journals.plos.org/plosbiology/article?id=10.1371/journal.pbio.1002564

Banschbach, V. S., Brubelle, A., Bartlett, K. M., Grivetti, J. Y., \& Yeamans, R. L. (2066). Tool use by the forest ant Aphaenogaster rudis: Ecology and task allocation. Insectes Sociaux, 53, 463-471. Retrieved from https://link.springer.com/article/10.1007/s00040-006-0897-2 DOI 10.1007/s00040-006-0897-2

Beck, B. (1973). Observation learning of tool use by captive Guinea baboons (Papio papio). American Journal of Physiology and Anthropology, 38, 579-582. Retrieved from https://www.ncbi.nlm.nih.gov/pubmed/4632107

Bentley-Condit, V. K., \& Smith, E. O. (2010). Animal tool use: current definitions and an updated comprehensive catalog. Behavior, 147, 185-221. https://doi.org/10.1163/000579509x12512865686555

Bussing, K. (2017). Clever ants use sponges and paper to transport honey. DOGOnews. Retrieved October 26, 2017, from https://www.dogonews.com/2017/3/15/clever-ants-use-sponges-and-paper-to-transport-honey.

Cammaerts, M.-C. (2013a). Sensu stricto individual conditioning, and imitation, in the ant Myrmica sabuleti (Hymenoptera, Formicidae). Annals of the Entomological Society of France, 49, 402-412. http://dx.doi.org/10.1080/00379271.2014.893679.

Cammaerts, M.-C. (2013b). Age dependent spatio-temporal learning in the ant Myrmica sabuleti (Hymenoptera, Formicidae). Bulletin de la Société Royale Entomologique Belge, 149, 205-212. Retrieved from www.srbe-kbve.be/sites/default/files/biblio_reprints_srbe_kbve.pdf

Cammaerts, M.-C. (2017a) Ants' ability in solving simple problems. International Journal of Biology, 9(3), 26-37. https://doi.org/10.5539/ijb.v9n3p26

Cammaerts, M.-C. (2017b) In a novel situation, ants can learn to react as never before - a preliminary study. Journal of Behavior, 2(2), 1011. Retrieved from https://www.jscimedcentral.com/Behavior/behavior -2-1011.php 
Cammaerts, M.-C. (2017c). Cognitive differences between conspecific ant colonies. Journal of Behavior, 2(1), 1005, 12p. Retrieved from https://www.jscimedcentral.com/Behavior/.../behavior-2-1005.pdf

Cammaerts, M.-C., \& Cammaerts, D. (2014).Comparative outlook over three Myrmica species' biotopes and foragers' know-how. Biologia, 69, 1051-1058. https://doi.org/10.2478/s11756-014-0399-Z

Cammaerts, M.-C., \& Cammaerts, R. (2015a). Are ants (Hymenoptera, Formicidae) capable of self recognition? Journal of Sciences, 5(7), 521-532. Retrieved from http://difusion.ulb.ac.be/vufind/Record/ ULB-DIPOT:oai:dipot.ulb.ac.be:2013/219269/Details

Cammaerts, M.-C., \& Cammaerts, R. (2015b) Ontogenesis of ants' cognitive abilities (Hymenoptera, Formicidae). Advanced Studies in Biology, 7, 335-348 + synopsis: 349-350. http://dx.doi.org/10.12988/asb.2015.54241

Cammaerts, M.-C., \& Cammaerts, R. (2016a). Spatial expectation of food location in an ant on basis of previous food locations (Hymenoptera, Formicidae). Journal of Ethology. https://doi.org/10.1007/s10164-016-0494-4

Cammaerts, M.-C., \& Cammaerts, R. (2016b). Ants can expect the time of an event on basis of previous experiences. ISRN Entomology, Article ID 9473128, 9 p. https://doi.org/10.1155/2016/9473128

Cammaerts, M.-C., \& Gosset, G. (2014). Impact of age, activity and diet on the conditioning performance in the ant Myrmica ruginodis used as a biological model. International Journal of Biology, l6(2), 10-20.

Cole, A. C., Jones, J. W., \& Jones, Jr. (1948). A Study of the Weaver Ant, Oecophylla smaragdina (Fab.). American Midland Naturalist, 39, 641-651. Retrieved from http://www.jstor.org/stable/2421529

Dejean, A., Solano, P. J., Ayroles, J., Corbara, B., \& Orivel, J. (2005). Arboreal ants build traps to capture prey. Nature, 434, 973. https://doi.org/10.1038/434973a

Fellers, J. H., \& Fellers, G. M. (1976). Tool-use in a social insect and its implications for competitive interactions. Science, 192, 70-72. Retrieved from https://www.researchgate.net/publication/6105458 DOI: 10.1126/science. 192.4234 .70

Haslam, M. (2013). Captivity bias in animal tool use and its implications for the evolution of hominid technology. Philosophical Transactions of the Royal Society of London, B Biological Sciences, 368, 2012.0421. https://doi.org/10.1098/rstb.2012.0421

Hölldobler, B., \& Wilson, E.O. (1990). The ants. Berlin. Springer Verlag. Retrieved from www.springer.com/gp/book/9783540520924.

Jost, J. P. (2015). La Communication et l'intelligence chez les animaux ou « Smart Faune ». Connaissances et Savoirs. Retrieved from https://www.connaissances-savoirs.com/la-communication-et-1-intelligence-chez -les-animaux-ou-smart-faune.html/

Karath, K. (2016). Ants craft tiny sponges to dip into honey and carry it at home. Animal Behaviour. https://doi.org/10.1016/j.anbehav.2016.11.005

Lörinczi, G. (2014). Some notes on the tool-using behaviour of the ant, Aphaenogaster subterranea (Hymenoptera: Formicidae). Tiscia, 40, 17-24. Retrieved from https://www.researchgate.net/.../286927061_Some_notes _on_the_tool-using_behaviour...

Loukola, O. J., Perry, C. J., Coscos, L., \& Chittka, L. (2017). Bumblenees show cognitive flexibility by improving on an observed complex behavior. Sciences, 355(6327), 833-836. Retrieved from http://dx.doi.org/10.1126/ science.aag 2360 .

Maáka, I., Lőrinczi, G., Le Quinquis, P., Módraa, G., Bovet, D., Call, J., \& d’Ettorre, P. (2017). Tool selection during foraging in two species of funnel ants. Animal Behavior, 123, 207-216. http://dx.doi.org/10.1016/ j.anbehav.2016.11.005

McFarland, D. (2009). Chp. 27. Intelligence, utilisation d'outils et culture. In: Le comportement animal. Psychobiologie, éthologie et évolution. Louvain-la-Neuve, De Boeck Supérieur, Ouvertures psychologiques. 543-560. Retrieved from http://www.cairn.info/le-comportement-animal--9782804107093-page-543.htm

Möglich, M. H. J., \& Alpert, G. D. (1989). Stone dropping by Conomyrma bicolor (Hymenoptera: Formicidae): a new technique of interference competition. Behavioral and Ecological Sociobiology, 6, 105-113. Retrieved from https://link.springer.com/article/10.1007/BF00292556

Morrill, W. L. (1972). Tool using behavior of Pogonomyrmex badius (Hymenoptera: Formicidae). Florida Entomologist, 55, 59-61. Retrieved from http://journals.fcla.edu/flaent/article/viewFile/56689/54368 
Passera, L. (2008). Le monde extraordinaire des fourmis. Paris. Librairie Arthème Fayard. Imprimerie Graficas Estella (Espagne). Retrieved from https://www.amazon.fr/monde-extraordinaire-fourmis-Luc-Passera/dp/ 2213634297

Pearce, J. M. (2008). Animal learning and cognition, an introduction. East Sussex, USA, Canada. Psychology Press. Retrieved from http://www.worldcat.org/title/animal-learning-cognition-an-introduction/oclc/ 682223995 .

Pierce, J.D. (1986). A review of tool use in insects. Florida Entomologist, 69, 95-104. https://doi.org/10.2307/ 3494748.

Shumaker, R. W., Walkup, K. R., \& Beck, B. B. (2011). Animal tool behavior: the use and manufacture of tools by animals. Baltimore. Johns Hopkins University Press. Retrieved from www.journals.uchicago.edu/doi/full/ $10.1086 / 663904$

Strausfeld, N. J. (1976). Atlas of an Insect Brain. Ed NJ Straufeld. Stringer-Verlag publisher. Retrieved from https://link.springer.com/book/10.1007\%2F978-3-642-66179-2

\section{Copyrights}

Copyright for this article is retained by the author(s), with first publication rights granted to the journal.

This is an open-access article distributed under the terms and conditions of the Creative Commons Attribution license (http://creativecommons.org/licenses/by/4.0/). 